\title{
APRESENTAÇÃO \\ DOSSIÊ: EDUCAÇÃO, EDUCADORES E INFÂNCIA
}

Marcia Cristina Argenti PEREZ1

Este número apresenta um dossiê temático: Educação, Educadores e Infância com artigos científicos produzidos por pesquisadores e colaboradores do Grupo de estudos e pesquisas sobre infância, família e escolarização -GEPIFE, da Universidade Estadual Paulista - UNESP CNPq.

As perspectivas temáticas dos autores estão ancoradas em teorias e pesquisas de diferentes áreas - pedagogia, psicologia, sociologia, linguística, política - que remetem à infância, como conceito socialmente oscilante no tempo e no espaço, e à criança e seus educadores, como sujeitos contextualizados.

O Dossiê inclui um conjunto de temáticas que tratam de processos de escolarização, da apropriação do conhecimento e desenvolvimento de subjetividades em situações sociais e escolares. Reconhece as crianças e seus educadores como sujeitos do conhecimento e, portanto, em condições de atuar criticamente nos modos de pensar e de produzir lugares para (re)significar as práticas educativas da infância. Os textos se empenham em problematizar temas como: conceito de infância, (in) visibilidade da paternidade, nativos digitais e a infância contemporânea, trajetórias escolares, cultura lúdica e gênero.

O primeiro texto: O pai e a escolarização dos filhos de autoria de Geraldo Romanelli desenvolve reflexões acerca das representações e das lacunas de estudos sobre a paternidade no processo de escolarização das crianças.

O segundo artigo: Teoria Crítica e infância: a caracterização do conceito no contexto de expropriação das experiências formativas de Andréa Calderan e Luiz Roberto Gomes versa sobre análises do conceito de infância à luz de autores da Teoria Crítica no contexto das influências da indústria cultura e da sociedade do consumo.

Nativos digitais: considerações sobre os alunos contemporâneos e a possibilidade de se (re)pensar a prática pedagógica de autoria de Thaís Cristina Rodrigues Tezani apresenta uma análise de estudos e dados empíricos sobre as mudanças e os desafios no processo educativo e nas interações sociais, mediadas pelas tecnologias dos nativos digitais.

${ }^{1}$ Universidade Estadual Paulista (Unesp), Faculdade de Ciências e Letras, Araraquara - SP - Brasil. Professora do Departamento de Psicologia da Educação. E-mail: marciacap@fclar.unesp.br. 
O texto de Luciana Ponce Bellido Giraldi intitulado: As trajetórias escolares: percepções de crianças/alunos e professoras retrata dados de estudo longitudinal referente as representações de crianças e professoras do Ensino Fundamental sobre as experiências escolares e o desempenho escolar.

O quinto artigo: Perspectivas lúdicas para o ensino de Ciências no início da educação fundamental de Aline Juliana Oja Persicheto oferece discussões relacionadas a importância do lúdico na prática docente como estratégia significativa no ensino de ciências no anos iniciais do ensino fundamental.

Ouvindo meninos: relações de gênero na educação infantil de Fernanda Ferrari Ruis e Marcia Cristina Argenti Perez apresenta dados de estudo de investigação e intervenção no contexto da Educação Infantil, com ênfase nas diferentes formas de ser menino, possibilitando análises sobre as relações de gênero na infância.

O sétimo artigo As contribuições do brinquedo de Miriti na construção sóciohistórico cultural da criança: "artefato cultural" de autoria de Suellen Silva Rodrigues, Andreza Marques de Castro Leão e Marcia Cristina Argenti Perez oferece a explanação de um estudo analítico-descritivo da cultura lúdica desenvolvida pelos ribeirinhos do Estado do Pará, sobretudo dos habitantes do município de Abaetetuba.

Da leitura dos trabalhos apresentados neste número, constatam-se ao menos duas certezas: a primeira, da complexidade de compreender a Infância e os processos eductivos aqui apresentados; a segunda, da impossibilidade de uma análise de Infância e Escolarização universal, considerando os diferentes temas e desdobramentos no tempo, no espaço e seus protagonistas. A essas certezas soma-se a expectativa: a de ter tornado visível a Infância e as práticas educativas, materializada a todos que lerem os artigos do Dossiê Temático e demais trabalhos publicados nesta edição.

Prof $^{a}$ Dr $^{\mathrm{a}}$ Marcia Cristina Argenti Perez Organizadora do Dossiê Temático 